\title{
9. Forecasting political developments with the help of financial markets Gerald Schneider
}

\section{INTRODUCTION}

It is a truism to say that forecasting political and economic trends continues to be a booming business (Sherden 1997). Within academia, however, many still conceive of prediction as a less noble task than explanation. The wide range of attitudes, between attraction and skepticism, leveled at professional forecasters can even be found among those who have transformed forecasting from an obscurantist business associated with astrology, crystal gazing, and "propheteering" into a key part of "normal science." The example of Oskar Morgenstern, one of the founders of modern game theory, illustrates this ambivalence nicely. In one of the earliest treatises on economic forecasting he stated apodictically: "Economic prognosis is ... impossible because of objective reasons" (Morgenstern 1928: 108, own translation). Yet, this co-founder of game theory and leading strategic analyst continued to publish on the topic and evaluated for instance the random walk thesis together with Nobel laureate Clive Granger (Granger and Morgenstern 1970).

Nevertheless, the acceptance and popularity of prediction as an academic endeavor vary greatly across social scientific disciplines. While the combination of explanation and prediction is the natural way to do research in demography or econometrics, political scientists are generally still hesitant to engage in this seemingly dirty business. One of the traditional reasons for this unwillingness has been the inaccuracy of standard techniques like opinion polling to forecast specific developments such as election outcomes.

Forecasting political events, however, no longer warrants this approach. The development of two techniques - betting markets and expert interviewbased decision models - has considerably changed the predictive accuracy of attempts to forecast the outcomes of political decision-making. In this chapter, I present an approach that marries some of the advantages that these two approaches offer. I test whether the collective information that 
financial markets contain can be used to predict both political developments and individual political events. To this end, I review recent contributions to the so-called Condorcet Jury Theorem which argues that collectives are better able to recognize the true state of the world than individual experts. I argue that financial markets can function like juries which discuss the available evidence in order to reach a correct decision (Coughlan 2000).

I use the political developments in the Levant, which has been, as we sadly all know, one of the most conflictive regions of the world throughout the past 60 years, to evaluate the predictive potential of financial markets within a political context. As severe political events such as the confrontations between Israel and its neighbors often have repercussions in the economies of the warring parties and elsewhere, we should expect that well-trained brokers serve as quasi-policy experts who build up scenarios over alternative political risks (Schneider and Troeger 2006a, 2006b). The anticipation of significant political events should, as a consequence, find its reflection in the price of securities and the buying and selling decisions that the financial intermediaries make. If a certain economically relevant event does not come as a complete surprise, it is thus ex ante contained in the price of a particular security. We can consequently conceive of financial markets as the aggregate opinion on the likelihood of alternative political scenarios that the financial intermediaries develop. The aggregate decision that traders make should be relatively accurate, not least because of the costs of faulty predictions. In contrast to interviewed policy experts who only occasionally have to fear a loss of reputation, financial traders will lose money if their decisions rely on erroneous political information. Yet, information from financial markets is not always useful for predictive purposes. The approach that I present here is not valid for the prediction of political developments: (1) which are economically not highly salient; (2) for which relevant decision-making information is restricted to a few policy insiders; and (3) in which many individual events come as surprises.

Using standard econometric techniques, I test the relative predictive accuracy of naive autoregressive models in predicting political events with competing models that contain information from financial markets. The evidence assembled shows that information from stock markets sensibly improves the predictive accuracy of models that largely rely on the auto-regression of the series under examination to produce forecasts. The lagged development of the Tel Aviv Stock Exchange allows me to predict the level of cooperation in the conflict between Israel and the Palestinians the following day more precisely than with an alternative model that just takes the lagged political interactions into account. Because violent events come much more often as a surprise than cooperative developments, the 
inclusion of financial market information does not improve the accuracy in the prediction of the daily level of conflict in the Middle East.

I organize this chapter as follows: I first review recent developments in the literature on political forecasting and develop a typology that allows me to see when a particular approach is adequate. Next, I present the research design and empirical evidence. I conclude with some recommendations and warnings on the technology that is introduced through this chapter.

\section{A TYPOLOGY OF RESEARCH STRATEGIES IN POLITICAL FORECASTING}

The traditional forecasting approach in the social sciences is based on econometrics and thus on the different scenarios that one can obtain from running competing statistical models. Yet, the predictions that a researcher is able to develop are as good as the information that is fed into the regressions. The requirement of a sound empirical footing of any forecast is particularly relevant for the analysis of key social or economic trends that are heavily influenced by a multitude of arcane decisions in various political settings. As neither reliable dynamic nor detailed micro-level information is obtainable for most decision-making processes, political econometrics often only resorts to crude macro-level indicators that do not vary much over time. Unsurprisingly, models of developments that are heavily shaped by political decisions, but rely on this limited empirical basis, often only provide shaky forecasts, as the experiences with the World Future reports of the 1970 s and 1980 s amply tell. The limited usefulness of macro-quantitative political data for predictive purposes is the reason why forecasts of political events frequently pursue different research strategies nowadays. They particularly base their predictions on information from individuals, be they explicit experts, quasi-experts working in another decision-making environment, or samples of the general population.

If political analysts base their predictions on judgmental information, they have to make two fundamental choices. The first decision relates to the question of whether or not the purpose of a research endeavor is the prediction of a single event or of a particular political development, which is simply a number of related events. A second consideration is whether the information gathered from few or many people is deemed to be more accurate for the particular forecasting problem under consideration. If one combines the decisions made along these two dimensions, one can distinguish four ideal types of judgment-based political forecasts, which I introduce in Figure 9.1. 


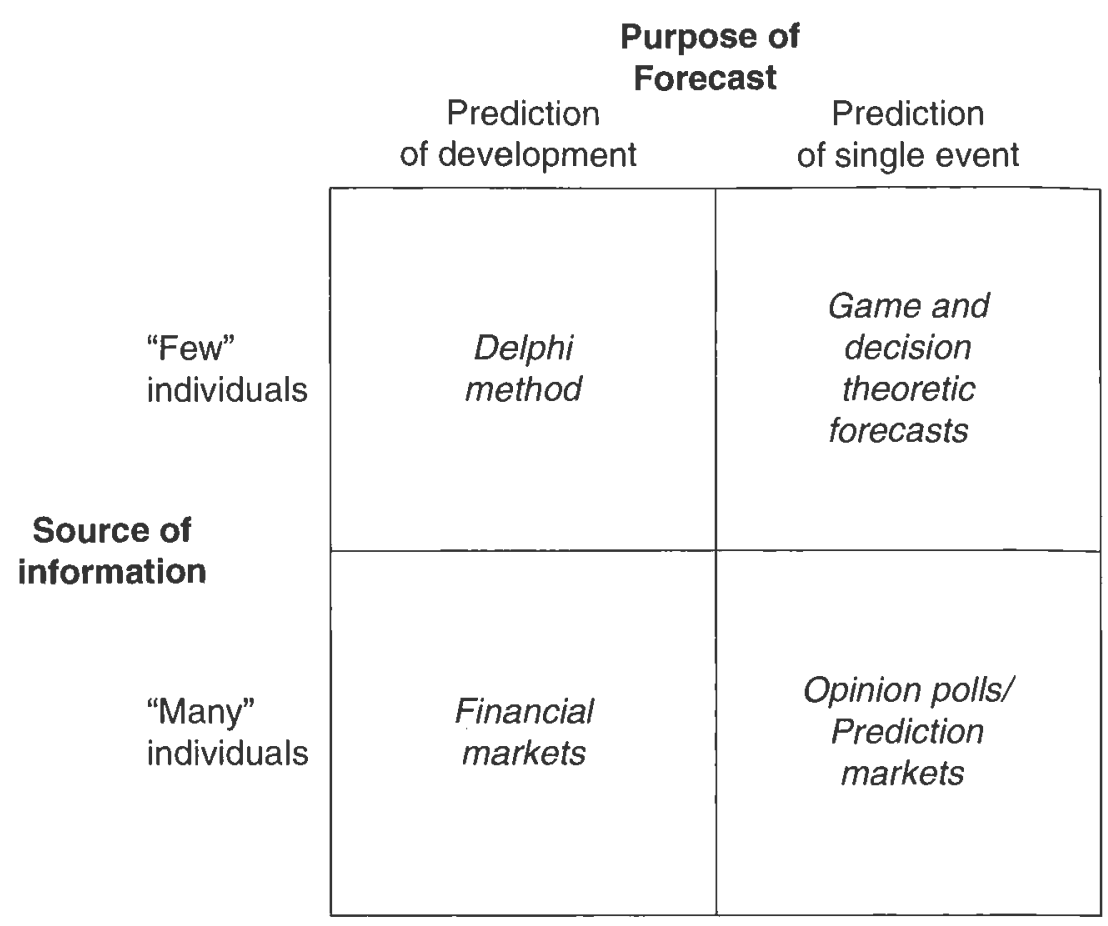

Figure 9.1 Ideal types of political forecasts with information from individuals

\section{Predictions Based on Few Individuals}

Single or small groups of experts are frequently used to predict scenarios for the development in a particular area. One of the key methodologies used is the Delphi method. The basic trick of this technology is to ask experts through repeated questionnaires what their opinion on a specific scenario is. Several authors have questioned the accuracy of this approach - "Delphi is undeserving of all of the attention it has received" (Armstrong 1978: 410) - while a recent survey comes to a more positive evaluation (Rowe and Wright 2001). Two particularly troublesome aspects of the approach are that the experts have to achieve a consensus and that the process through which they arrive there is not explicitly modeled.

This problem is circumvented in the forecasting approach that Bueno de Mesquita has introduced based on his expected utility approach to decisions on war and peace. Within this model-based framework, the opinion of the expert is only used as an input for a forecasting tool that 
has its foundations in decision and game theory (e.g. Bueno de Mesquita et al. 1985; Bueno de Mesquita 2002). This approach has been applied to a variety of issues and also to some evaluations by like-minded scholars (Bueno de Mesquita and Stokman 1994; Stokman and Thomson 2004). ${ }^{1}$ The relative predictive accuracy of the models is impressive. Feder (1995; see also Ray and Russett 1996) reports a success rate of 90 percent for the analyses that the US Central Intelligence Agency (CIA) had commissioned. In a recent evaluation of the predictive accuracy of this and related game-theoretic models, other approaches based on standard bargaining models, however, performed slightly better (Thomson et al. 2006; Schneider et al. 2005).

The main advantage of the forecasting approach pioneered by Bueno de Mesquita is that the level of expertise that is required from an interview partner is modest and only relates to an evaluation of the present. Hence, game-theoretic models that are used to produce forecasts rely on the estimates that the interviewed expert provides with regard to the actors' preferences, power, and the importance they attach to the various contested issues. As Bueno de Mesquita (2002: 69) argues, the validity of the expert judgment is a less crucial aspect than one might think: "it turns out that the vast majority of specialists basically view this information in the same way." To search for detailed information that only a few experts can provide seems particularly adequate for the analysis of decision-making situations where the informed public is unable to locate the intentions and the power of key decision-makers. Yet, the incentive of the expert to deliver precise information is modest, and the interviewer has often no real chance to verify how accurate the expert estimates are. As I will argue below, there are thus certain situations in which the reliance on a pool of less qualified experts rather than some selected key informants seems desirable.

\section{Predictions Based on Many Individuals}

The main reason as to why financial market information should improve forecasts for some political developments depends on the costliness of the decisions that traders make. A broker includes relevant economic and political information when deciding about selling or buying a particular security. If a financial market depends heavily on political decisions, traders build up expectations about the likelihood of certain scenarios in the political realm. A typical example is whether or not a left-wing or a right-wing party will be elected into government in an upcoming election. As the announced economic policies of these competing political forces differ, neglecting the possibility that an election might be more or less favorable to particular financial transactions is highly risky. Even if 
market participants are not completely "rational" in the technical sense of the term, they will try to anticipate important political events and developments. A large number of studies have shown in this vein that markets systematically include relevant information from an ongoing electoral campaign (e.g. Leblang and Mukherjee 2005). In addition, I have shown in collaborative work with Vera Troeger that world stock markets have reacted systematically to escalatory and de-escalatory moves in three conflicts throughout the 1990s (Schneider and Troeger 2006a, 2006b). As some of the events are easily foreseeable, like upcoming party congress speeches or meetings between heads of states, it would be irrational for traders to refrain from partly anchoring their current buying and selling decisions on an anticipated political event that will have economic repercussions.

The Condorcet Jury Theorem (CJT) provides a theoretical rationale for my assertion that a large number of non-experts can on some occasions provide more accurate forecasts on political developments than the average individual expert. In my view, financial markets function like large decision-making committees that have to decide between competing hypotheses about the future. To deal with this form of belief rather than preference aggregation, the reliance on the CJT seems especially appropriate. The CJT states, in its canonical version, that the competence of a group in recognizing $p$, the true state of the world, is larger than the average individual competence. Further, this collective capability approximates 1 if the size of the committee grows. Large committees like the traders assembled in a financial market would accordingly be able to reach almost "correct" decisions in situations where the decision-makers share the same fundamental preference, but receive different information about the state of the world. ${ }^{2}$

It should be noted, however, that the CJT does not generally hold. Berg (1993) showed that the collective competence might be smaller than that of the average individual if the individual beliefs are correlated. Furthermore, the collective does not increase its competence if the number of marginally competent individuals ( $p$ slightly larger than 0.5 ) increases (Paroush 1998). In a world of strategic rather than "sincere" traders, the collective wisdom can be more erroneous than the average individual decision (Austen-Smith and Banks 1996). ${ }^{3}$ As Feddersen and Pesendorfer (1998) demonstrate, unanimity and thus the consensus opinion to which herding traders refer might be the worst decision-making rule from an informational perspective. Their hypothesis that a curvilinear relationship between the decision-making quorum and the error probabilities exists, receives empirical support in the experiments by Guarnaschelli et al. (2000). Yet, Coughlan (2000) qualifies this result and shows that unanimity is the most information-efficient decision-making rule if a jury faces the risk that a 
mistrial occurs - no unanimous decision is reached - or if its members are able to communicate their private information.

I assume for my empirical application along these lines that financial markets can be conceived of as a collective decision-making body that also evaluates those political processes that are important for the development of the securities. Even though the traders are far from being well-informed experts in a certain election, a militarized dispute between two states, or the economic policy-making process of a certain country, they have considerable incentives to inform themselves about the possible outcomes of important collective political decisions. Most importantly, they talk with each other about the different scenarios so that the anomalies of judgment aggregation uncovered by Austen-Smith and Banks as well as Feddersen and Pesendorfer (1998) do not matter. If traders refrain from building sensible forecasts about important political developments, they jeopardize the value of securities they are trading with and possibly also harm their personal careers. If a political process is thus relatively easy to understand and economically relevant, they will build up collective forecasts that can be used to predict the ups and downs in the political arena.

Obviously, markets can be wrong in their assessments. In an early application, Bueno de Mesquita (1990) uses the money market discount rate as an indicator for the anticipated costs of conflict to evaluate the expectations contemporary agents had over the confrontations between Austria and Prussia in the nineteenth century. Analyzing the Seven Weeks War and the crucial battle at Königsgrätz, he writes:

This reinforces the widely reported observation that Prussia was expected to lose the war ... the expectations in the financial markets were updated to take account of the new information revealed on the battlefield - that the market had underestimated Prussia's chance of victory. The prewar fears of postwar inflation or of defaults on money instruments by a defeated Prussia were allayed by Prussia's decisive victory. (Bueno de Mesquita 1990: 44-45)

This chapter pursues a similar line of inquiry and asks whether stock market data can be used to forecast the political climate of the Levant. This conflict, which has been dominated by the confrontation between Israel and the Palestinians throughout the past six decades, certainly belongs to the category of disputes that have consequences for the world economy (Schneider and Troeger 2006a) as well as individual sectors (e.g. Fleischer and Buccola 2002; Schneider and Troeger 2006b). As the developments within this conflict region are well reported, several researchers have attempted to forecast escalations for the various dyads (e.g. Schrodt and Gerner 2000). These forecasts, however, are largely atheoretical. Based on a variety of methodological tools, these applications typically use past 
information from this conflict region to predict future patterns of interaction. This chapter moves beyond the tradition of solely relying on autoregressive models to produce predictions by including information from a collective quasi-expert - the stock market - in the regression.

\section{RESEARCH DESIGN}

This chapter examines whether aggregate financial market indicators improve the predictive accuracy of time series models that only rely on the characteristics of the series itself. For this purpose, I will use a key index of the Tel Aviv Stock Exchange, the TA 100, to evaluate whether financial traders can be conceived as a collective decision-making body which assesses the probability of different political scenarios in the Levant. The application aggregates the TA 100 data at the daily level and regresses it on two indicators of Levant conflict: sum of cooperation and sum of conflict. I have used the data on Levant conflict that was collected by the Kansas Event Data System (KEDS). ${ }^{4}$ This prominent collection of event datasets has already served as the empirical basis for some predictive inquiries (e.g. Pevehouse and Goldstein 1999; Schrodt and Gerner 2000). As is common with event data, the events identify the "sender" and the "target" of a cooperative or conflictive act within a dyad of political actors. The outcome variables used in this chapter summarize the information across all relevant dyads in the Levant from January 1, 1990, to June 30, 2004.

To predict the daily level of cooperation and conflict, I will use autoregressive moving average (ARMA) $(1,0)$ and $\operatorname{EGARCH}(1,1)$ models. The former approach includes an autoregressive parameter to predict the mean of cooperation and conflict. The latter technique is based on a standard tool within financial econometrics, the generalized autoregressive conditional heteroskedasticity (GARCH) models due to Bollerslev (1986) and Engle (1982; see also Beck 1983).

The usage of a GARCH model is appropriate because the error variance of the conflict and cooperation series varies over time. ${ }^{5}$ Hence, in an intensive political conflict like the one going on in the Middle East for more than six decades, events of a particular type often come in clusters so that periods of high volatility follow periods of low volatility. This simply means for the conflict in the Levant that "bad days" in the form of a bomb attack are most likely followed by another violent episode in the next time period, while a cooperative gesture typically triggers another conciliatory move the next day. The canonical GARCH $(1,1)$ model uses two parameters, the error coefficient $\alpha$ and the lag coefficient $\beta$, in the conditional 
variance equation that is added to the prediction of the mean of the series under examination. ${ }^{6}$

GARCH models assume a symmetric effect of positive and negative errors on the volatility of the series. To control for asymmetric responses in the variance to positive and negative developments, I will examine the appropriateness of a modification of the GARCH model, the socalled exponential general autoregressive conditional heteroskedasticity (EGARCH) approach developed by Nelson (1991). ${ }^{7}$ The assumption of asymmetric responses was appropriate in a related inquiry in which we attempted to predict the reactions of stock markets to both cooperative and conflictive events in three conflicts (Schneider and Troeger 2006a, 2006b).

The stock market variable is differenced because high-frequency financial data, such as daily stock market indices, exchange or interest rates, are almost always driven by stochastic processes. ${ }^{8}$ The stock market information is included in the mean equation of the models that test the main conjecture of this chapter; I include in all models an autoregressive term to predict the sum of conflict or cooperation that occurred the next day within the overall conflict region. The statistical models also include the lagged variable "bad day" for the calculation of the variance equation. This is in line with the expectation that particularly conflictive events increase the uncertainty of the traders with the effect that the volatility of the series grows. Note that the estimations refer to the same number of cases so that the statistical models are truly comparable. Summary statistics of the data used for the analysis can be found in the Appendix.

\section{THE PREDICTION OF THE DAILY SUM OF COOPERATION AND CONFLICT}

Conflict in the Levant has followed a largely erratic pattern throughout the period under observation. Figure 9.2(a) depicts the daily net sum of cooperation, which stands for the difference between the absolute values of cooperation and conflict. Sparks of cooperation are visible in the mid-1990s when the Oslo Peace Process stirred the hope of a permanent settlement between Israel and the Palestinian Liberation Organization (PLO). The Madrid conference of October 1991 did not lead to a similarly positive eruption of cooperation; this mediation attempt by the USA and the USSR took place at the end of the conflict between the Western-led alliance against Saddam Hussein which also - together with events associated with the first Intifada which was then waning out - instigated considerable turbulence in the Levant. The magnitude of these largely conflictive 
(a) Net daily cooperation (Goldstein scores)

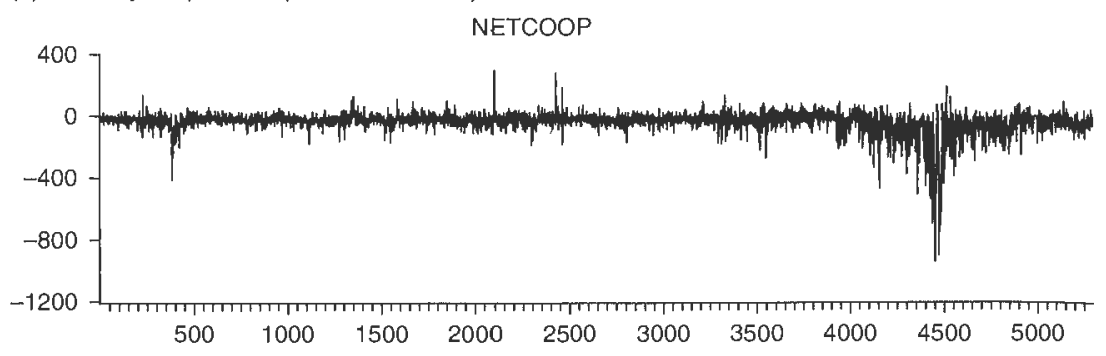

(b) TA100

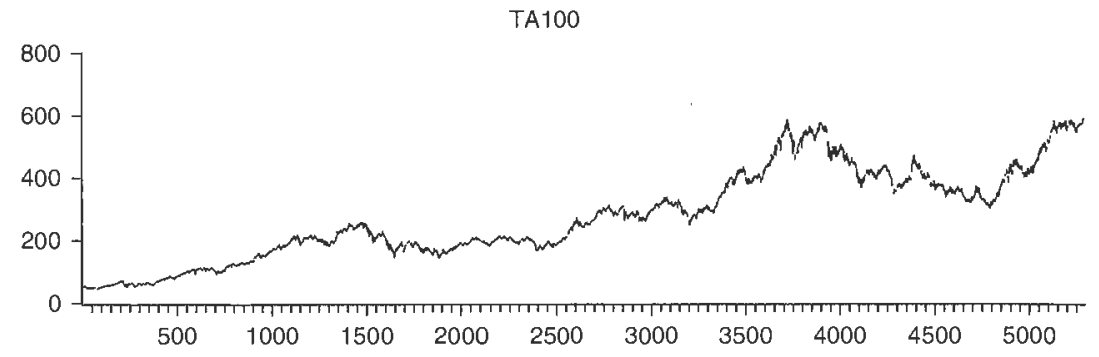

Figure 9.2 Conflict and cooperation in the Levant and the Tel Aviv Stock Exchange, January 1, 1990 to June 30, 2004

clusters of events, however, never reached the magnitude of conflict that the second Intifada brought to the region. The visit of Ariel Sharon, who was then leader of the Likud party, to the Temple Mount was among the catalytic events in this confrontation.

In contrast to the conflict data the stock market series depicted in Figure 9.2(b) shows a clear trend. The TA 100 has grown steadily throughout the 1990s, interrupted by a short downturn in 1993. Similar to the world markets, the TA100 peaked shortly after the beginning of the new decade. An abrupt fall was followed by a short recovery and a longer crisis. The Tel Aviv stock exchange, however, rebounded again in early 2003.

As the political and the financial series are visually not related in any meaningful way, we need statistical tools to estimate the impact of lagged cooperative and conflictive events on the TA100. To this end, I present in Table 9.1 the results of four ARMA $(1,0)$ and EGARCH $(1,1)$ models. The dependent variables are the daily sum of cooperation across all dyads in the region and the equivalent measure for the daily level of conflict, which is coded negatively. The full models that I calculated for all different outcome variables include the differenced and lagged stock market 
Table 9.1 The impact of the lagged stock market exchange on conflict between Israel and the Palestinians, January 5 , 1990 to June 25, 2004 (ARMA $(1,0,0)$ and EGARCH $(1,1)$ models)

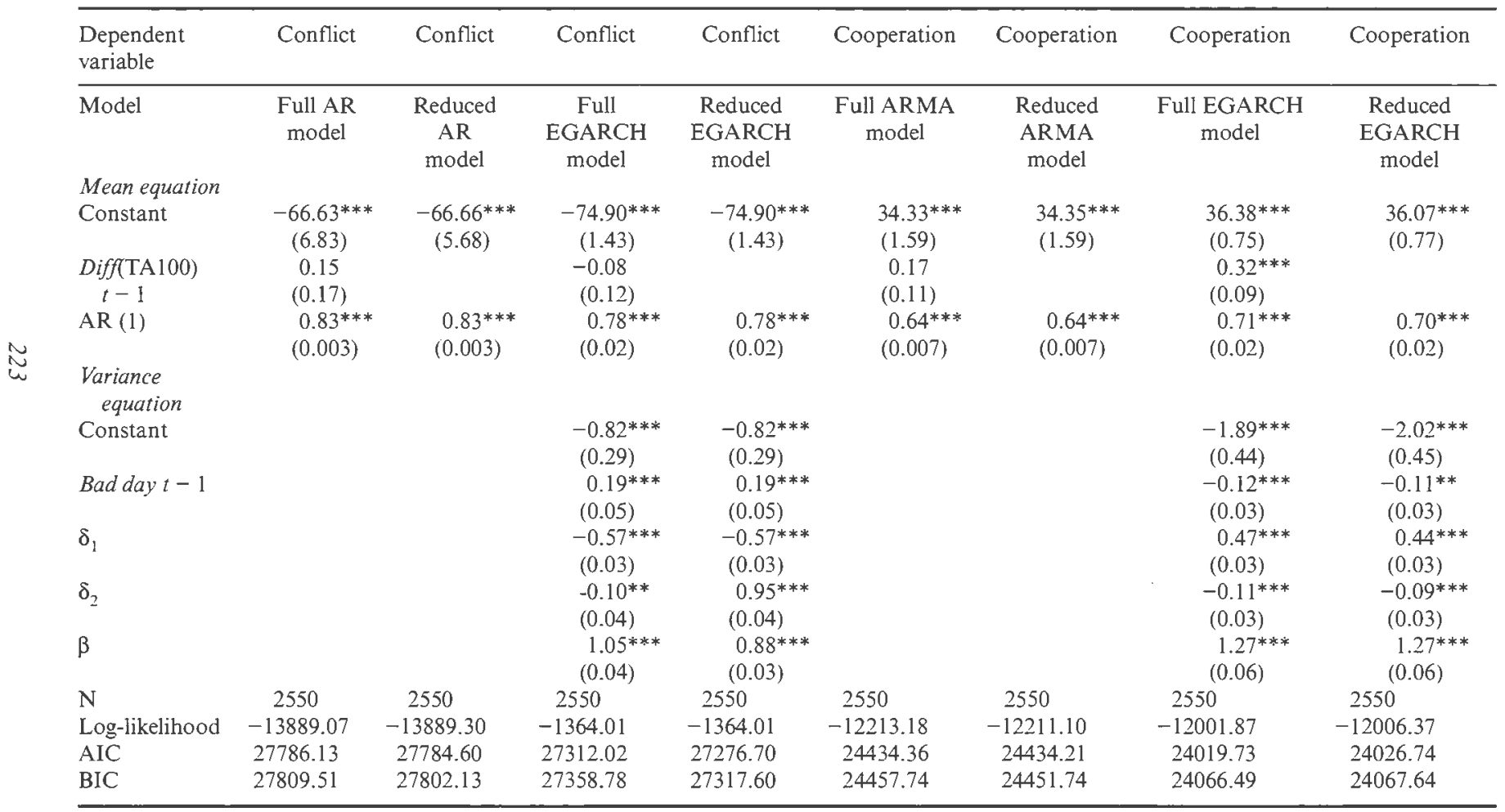

Note: $* * *, * *$, and $*$ denote significance levels at $1 \%, 5 \%$, and $10 \%$. Entries are parameter estimates and robust standard errors. 
information; the reduced ARMA and EGARCH models, by contrast, only use autoregressive parameters.

The results reported in Table 9.1 clearly demonstrate that the stock market can be partly used to predict political developments in the Levant. However, this is only the case for cooperative events, not conflictive ones, and even there, the results are not always completely convincing. The divergence in the capacity of the stock market to predict well across different types of events certainly does not come as a complete surprise. In general, conflict is harder to predict than cooperation. If surprising conflictive events like bombings were foreseeable, they would not happen - or at least not that often. The relationship between the lagged and differenced TA 100 series and the cooperation series means that traders anticipate cooperative events before they are actually going to happen. The calculations suggest that the substantive effect of a one-point rise in the main Tel Aviv stock market index is followed by a 0.32 increase in the sum of cooperation across all Levant dyads the next day. A similar, but somehow reduced and statistically only marginally significant effect, is observable for the autoregressive model.

The analysis also shows that both conflict and cooperation are highly autoregressive processes. Furthermore, there is strong evidence that the cooperation and conflict series share some of the characteristics of the high-frequency data typically analyzed in financial econometrics. The parameter estimations for the variance equations in the EGARCH models show that particularly bad days increase the volatility of the conflict series and decrease the variance with regard to the net sum of cooperative events. This latter result can easily be explained through the tendency of severe events to render cooperation less likely, thus reducing the level of cooperation and, simultaneously, the volatility of this series. The first d-parameter in the estimation of the cooperation series similarly indicates that conflictive shocks have a strong effect on the series variance.

The analysis conducted so far leads to the question of whether or not one can predict particular events well with the approach pursued in this chapter. I will try to do so in the following through the usage of simple forecasting models that try to predict the level of cooperation that happened the next day. I will compare the predictive accuracy of the EGARCH $(1,1)$ and the autoregressive models that either include the stock market information or do not. The events that I have selected for exploring the ability of stock market data to deliver point predictions for political events are the salient cooperative events listed in Schneider and Troeger (2006a) and some of the key cooperative events that happened outside their period of examination from 2000 to the end of June 2004. 
Table 9.2 reports the predicted values of the four models and the real sum of cooperation that was observed on a particular day. Note that I have chosen the next day with a forecast in cases where the Tel Aviv stock market was closed on the day during which a particularly cooperative event happened.

The attempt to forecast individual cooperative events with four different statistical models largely confirms the earlier reported result that the EGARCH model with the lagged stock market information provides the most accurate forecasts. In eight of the 12 chosen events, its point predictions came closest to the real sum of cooperation. However, the inclusion of the financial market series does not make much of a difference as the atheoretical EGARCH model came up seven times with either the best or the second-best forecast. In general, the predicted values underestimate the level of cooperation that occurred on these particularly significant days. The mean average error of the forecasts is thus, to put it more technically, quite considerable. This does not, however, undermine the general message of this chapter, according to which a pool of quasi-experts - like the traders on a stock market - can in some instances be used to forecast political trends and events.

\section{CONCLUSION}

Forecasting political developments has for a long time been left to area experts, mediagenic academics or the infamous taxi-driver that the busy journalist selected for his journey from the airport to the downtown hotel. Fortunately, some recent methodological advances allow us to move beyond this dire state of affairs and to make forecasting a routine part of academic inquiry in the social sciences. This chapter adds to this emerging literature by trying to systematically predict conflictive and cooperative patterns of interactions in the Levant, one of the regions in which the interactions between the various political forces are among the most volatile in the world.

The goal of this chapter was largely theoretical rather than methodological. I particularly attempted to show that political forecasting should rely on the judgment of many rather than a selected few experts in situations in which large collectives build an opinion on a particular political development. In my view, this is particularly the case for decisions on war and peace that affect the lives and well-being of many individuals. In the case of the Levant, one of the appropriate juries to gauge systematic forecasts is the financial community. As escalations and de-escalations on the Levant have important political and economic repercussions around the world, I 
Table 9.2 Point predictions of AR-model and the stock market model

\begin{tabular}{|c|c|c|c|c|c|}
\hline Cooperative Event & $\begin{array}{c}\text { Actual } \\
\text { sum of } \\
\text { cooperation }\end{array}$ & $\begin{array}{l}\text { Prediction } \\
\text { (full ARMA } \\
\text { model) }\end{array}$ & $\begin{array}{l}\text { Prediction } \\
\text { (reduced } \\
\text { ARMA } \\
\text { model) }\end{array}$ & $\begin{array}{l}\text { Prediction } \\
\quad \text { (full } \\
\text { EGARCH } \\
\text { model) }\end{array}$ & $\begin{array}{l}\text { Predicted } \\
\text { (reduced } \\
\text { EGARCH } \\
\text { model) }\end{array}$ \\
\hline $\begin{array}{l}\text { Madrid peace } \\
\text { conference (October } \\
30,1991)\end{array}$ & 40.7 & 29.9 & 28.4 & 35.9 & 28.4 \\
\hline $\begin{array}{l}\text { Secret Agreement in } \\
\text { Oslo announced } \\
\text { (August 30, 1993) }\end{array}$ & 51.5 & 31.01 & 30.71 & 37.11 & 36.1 \\
\hline $\begin{array}{l}\text { Israel and PLO sign } \\
\text { Oslo I agreement } \\
\text { (September 13, } \\
\text { 1993) }\end{array}$ & 112.2 & 45.0 & 45.9 & 34.5 & 36.1 \\
\hline $\begin{array}{l}\text { Israel and PLO sign } \\
\text { "Gaza-Jericho First" } \\
\text { agreement (May 4, } \\
1994)^{2}\end{array}$ & 59.5 & 12.01 & 12.21 & 10.31 & 10.9 \\
\hline $\begin{array}{l}\text { Israeli and PLO } \\
\text { negotiators in Taba } \\
\text { achieve partial } \\
\text { agreement (August 11, } \\
\text { 1995) }\end{array}$ & 64.9 & 49.7 & 49.6 & 51.8 & 51.4 \\
\hline $\begin{array}{l}\text { "Summit of the } \\
\text { Peacemakers" at } \\
\text { Sharm el-Sheikh } \\
\text { (March 13, 1996) }\end{array}$ & 63.6 & 30.5 & 30.0 & 31.2 & 30.2 \\
\hline $\begin{array}{l}\text { Israel and PA sign Wye } \\
\text { River Memorandum } \\
\text { (October 23, 1998) }\end{array}$ & 120.3 & 68.4 & 67.9 & 72.8 & 71.2 \\
\hline $\begin{array}{l}\text { Israel and the PA } \\
\text { sign Sharm el- } \\
\text { Sheikh Agreement } \\
\text { (September 4, 1999) }\end{array}$ & 34.8 & 28.9 & 28.9 & 36.4 & 36.1 \\
\hline $\begin{array}{c}\text { Camp David summit } \\
\text { begins }(11 / 7 / 00)\end{array}$ & 76.7 & 34.0 & 34.6 & 35.1 & 36.1 \\
\hline $\begin{array}{l}\text { Camp David summit } \\
\text { ends in failure (July } \\
25,2000)\end{array}$ & 52.3 & 36.3 & 36.3 & 36.3 & 36.1 \\
\hline $\begin{array}{l}\text { Abbas to become first } \\
\text { Palestinian Prime } \\
\text { Minister (March 19, } \\
\text { 2003) }\end{array}$ & 28.1 & 50.6 & 51.2 & 35.22 & 36.1 \\
\hline $\begin{array}{l}\text { Roadmap peace plan } \\
\text { launched (April 30, } \\
\text { 2003) }\end{array}$ & 120.4 & 44.1 & 42.5 & 47.0 & 43.7 \\
\hline
\end{tabular}


Table 9.2 (continued)

\begin{tabular}{lccccc}
\hline Cooperative Event & $\begin{array}{c}\text { Actual } \\
\text { sum of } \\
\text { cooperation }\end{array}$ & $\begin{array}{c}\text { Prediction } \\
\text { (full ARMA } \\
\text { model) }\end{array}$ & $\begin{array}{c}\text { Prediction } \\
\text { (reduced } \\
\text { ARMA } \\
\text { model) }\end{array}$ & $\begin{array}{c}\text { Prediction } \\
\text { (full } \\
\text { EGARCH } \\
\text { model) }\end{array}$ & $\begin{array}{c}\text { Predicted } \\
\text { (reduced } \\
\text { EGARCH } \\
\text { model) }\end{array}$ \\
\hline $\begin{array}{l}\text { Sharon orders a plan } \\
\text { be drawn up to } \\
\text { remove Gaza strip } \\
\text { settlements (February }\end{array}$ & 37.8 & 35.2 & 34.4 & $\mathbf{3 8 . 1}$ & $\mathbf{3 6 . 1}$ \\
$2,2004)^{5}$ & & & & & \\
\hline
\end{tabular}

Noles:

Best prediction in bold, second-best in bold and italics, worst in italics. The cooperative cvents listed in Schneider and Troeger (2006a) and in a BBC chronology on the Middle East conllict were used as sources.

1 Actual and predicted values from August 31, 1993.

2 Actual and predicted valucs from May 5, 1994.

3 Actual and predicted values from Scptember 7, 1999

4 Actual and predicted values from March 21, 2003.

5 Actual and predicted values from February 3, 2004.

can assume that financial markets try to anticipate the change of tide in this conflict region.

I have used recent research on the Condorcet Jury Theorem to argue that we can perceive financial markets as collective deliberative decisionmaking bodies whose predictions can be more accurate than the forecasts of individual policy experts. The usage of GARCH and simple autoregressive models has confirmed that we can use the lagged stock market information to forecast political developments. In particular, the analysis has shown that financial markets forecast cooperative events, but not necessarily conflictive ones. Hence, although we might rely on financial markets to predict positive developments, the financial community is often not good at predicting what security services, the military, and the media are also especially bad in auguring: violent conflict.

\section{ACKNOWLEDGMENTS}

I would like to thank the European Commission under the 6th Framework Programme (Project CIT-2-CT-2004-506084) for partial funding and the conference participants - especially Bruce Bueno de Mesquita, J. David Singer, and Frank Wayman - for their comments. Able research assistance by Peter Hille and Matthias Holzner is gratefully acknowledged. 


\section{NOTES}

1. Since expert judgment is only used as a data input, the empirical basis could also consist of macro-political information. I have pursued this alternative strategy to test the predictive accuracy of a game-theoretic model in an application of competing bargaining models on international economic negotiations (Schneider 2005).

2. The CJT assumes: (a) that the average competence p exceeds 0.5 ; (b) that their judgments are independent of each other; and (c) that they "vote" for one state of the world in a sincere fashion. See Grofman and Feld (1988), Young (1988), and Lada (1992) for introductions.

3. The main assumption behind this counterintuitive result is that the signals that committee members receive about "reality" arc at least partly private. A strategic voter has, in this insplicit voting modcl, an intcrest to cast the decisive vote, while a sincere jury member always follows the private information he or she possesses. Technically, the Austen-Smith and Banks models means that sinccre voting is generally not a Nash equilibrium and the collective ability to choose the "correct" solution is less than the average individual ability.

4. The machine-coded event dataset, of which I have used an update from 2004, was screened for possible coding errors before the analysis. A few events, like for instance a report on a soccer game, were excluded from the dataset that was used in the analysis. A more recent Levant dataset can be found on the KEDS website (http://www. ku.edu/ keds/, last consulted May 16, 2006).

5. Engle (2001) is one of the many introductions to these modcling tools.

6. Formally, the conditional variance equation in the $\operatorname{GARCH}(1,1)$ model takes the following form: $\sigma_{t}^{2}=\omega+\alpha \varepsilon_{t-1}^{2}+\beta \sigma_{t-1}^{2}$ here $\omega$ is the GARCH constant.

7. The conditional variance equation of the E-GARCH model looks as follows:

$$
\log \left(\sigma_{t}^{2}\right)=\varpi+\delta_{1}\left|\frac{\varepsilon_{t-1}}{\sqrt{\sigma_{t-1}^{2}}}\right|+\delta_{2} \frac{\varepsilon_{t-1}}{\sqrt{\sigma_{t-1}^{2}}}+\beta \log \left(\sigma_{t}^{2} \quad\right)
$$

Asymmetry can be observed in case $\delta_{2}$ differs significantly from 0 .

8. As the respective tests statistics have shown, neither unit-root (Phillips-Perron and Dickey-Fuller tests) nor co-integration (Johansen test) problems hampered this analysis.

\section{REFERENCES}

Armstrong, J. Scott (1978) Long Range Forecasting: From Crystal Ball to Computer. New York: Wiley.

Austen-Smith, David and Jeffrey S. Banks (1996) "Information Aggregation, Rationality and the Condorcet Jury Theorem," American Political Science Review 90(1): 34-45.

Beck, Nathaniel (1983) "Time-Varying Parameter Regression Models," American Journal of Political Science 27(3): 557-600.

Berg, Sven (1993) "Condorcet's Jury Theorem, Dependency among Jurors," Social Choice and Welfare 10: 87-96.

Bollerslev, Tim (1986) "Generalised Autoregressive Conditional Heteroskedasticity," Journal of Econometrics 31: 307-327.

Bueno de Mesquita, Bruce (1990) "Pride of Place: The Origins of German Hegemony," World Politics 43: 28-52.

Bueno de Mesquita, Bruce (2002) Predicting Politics. Columbus, $\mathrm{OH}$ : Ohio State University Press. 
Bueno de Mesquita, Bruce, David Newman, and Alvin Rabushka (1985) Forecasting Political Events. New Haven, CT: Yale University Press.

Bueno de Mesquita, Bruce and Frans Stokman (eds) (1994) European Community Decision Making: Models, Applications, and Comparisons. New Haven, CT: Yale University Press.

Coughlan, Peter J. (2000) "In Defense of Unanimous Jury Verdicts: Mistrials, Communication and Strategic Voting," American Political Science Review 94: 375-393.

Engle, Robert (1982) "Autoregressive Conditional Heteroskedasticity with Estimates of the Variance of UK Inflation," Econometrica 50: 987-1008.

Engle, Robert (2001) "GARCH 101: An Introduction to the Use of ARCH/ GARCH Models in Applied Econometrics," Journal of Economic Perspectives 15: $157-168$.

Feddersen, Tim and Wolfgang Pesendorfer (1998) "Convicting the Innocent: The Inferiority of Unanimous Jury Verdicts," American Political Science Review 92 : 23-35.

Feder, Stanley (1995) "Factions and Policaon: New Ways to Analyze Politics," in H. Bradford Westerfield (ed.), Inside CIA's Private World: Declassified Articles from the Agency's Internal Journal, 1955-1992. New Haven, CT: Yale University Press, pp. 274-322.

Fleischer, Aliza and Steven Buccola (2002) "War, Terror, and the Tourism Market in Israel," Applied Economics 34(11): 1335-1343.

Granger, Clive W.J. and Oskar Morgenstern (1970) Predictability of Stock Market Prices. Lexington, MA: Heath.

Grofman, Bernard and Scott L. Feld (1988) "Rousseau's General Will: A Condorcetian Perspective," American Political Science Review 82(2): $567-576$.

Guarnaschelli, Serena, Richard D. McKelvey and Thomas R. Palfrey (2000) "An Experimental Study of Jury Decision Rules," American Political Science Review 94(2): 407-424.

Lada, Krishna K. (1992) "The Condorcet Jury Theorem, Free Speech, and Correlated Votes," American Journal of Political Science 36: 617-634.

Leblang, David and Bumba Mukherjee (2005) "Government Partisanship, Elections and the Stock Market: Examining American and British Stock Returns, 1930-2000," American Journal of Political Science 49(4): 780-802.

Morgenstern, Oskar (1928) Wirtschaftsprognose. Eine Untersuchung ihrer Voraussetzungen und Möglichkeiten (Economic Prognosis. An Examination of its Conditions and Possibilities). Vienna: Julius Springer.

Nelson, Daniel B. (1991) "Conditional Heteroskedasticity in Asset Returns: A New Approach," Econometrica 59(2): 347-370.

Paroush, Jacob (1998) "Stay Away from Fair Coins: A Condorcet Jury Theorem," Social Choice and Welfare 15(1): 15-20.

Pevehouse, Jon C. and Joshua S. Goldstein (1999) "Serbian Compliance or Defiance in Kosovo? Statistical Analysis and Real-Time Predictions," Journal of Conflict Resolution 43(4): 538-546.

Ray, James Lee and Bruce Russett (1996) "The Future as Arbiter of Theoretical Controversies: Predictions, Explanations and the End of the Cold War," British Journal of Political Science 26(4): 441-470.

Rowe, Gene and George Wright (2001) "Expert Opinions in Forecasting Role of the Delphi Technique," in J.S. Armstrong (ed.), Principles of Forecasting: 
Handhook for Researchers and Practitioners. Norwell, MA: Kluwer Academic Publishers, pp. 125-144.

Schneider, Gerald (2005) "Capacity and Concessions: Bargaining Power in Multilateral Negotiations," Millennium 33(3): 665-690.

Schneider, Gerald, Daniel Finke and Stefanie Bailer (2005) "Bargaining Power in the European Union: An Evaluation of Competing Approaches," unpublished, University of Konstanz.

Schneider, Gerald and Vera E. Troeger (2006a) "War and the World Economy: Stock Market Reactions to International Conflicts, 1990-2000," Journal of Conflict Resolution 50(5): 623-645.

Schneider, Gerald and Vera E. Troeger (2006b) "Winners and Losers of War: Evidence from Three Stock Markets," unpublished working paper.

Schrodt, Philip A. and Deborah J. Gerner (2000) "Using Cluster Analysis to Derive Early Warning Indicators for Political Change in the Middle East, 1979-1996," American Political Science Review 94(4): 803-818.

Sherden, William A. (1997) The Fortune Sellers: The Big Business of Buying and Selling Predictions. Hoboken, NJ: Wiley.

Stokman, Frans and Robert Thomson (2004) "Winners and Losers in the European Union," European Union Politics 5(1): 5-23.

Thomson, Robert, Frans N. Stokman, Christopher H. Achen, and Thomas König (2006) The European Union Decides. Cambridge: Cambridge University Press.

Young, H.P. (1988) "Condorcet's theory of voting," American Political Science Review 82(4): 1231-1244. 


\section{APPENDIX}

Table 9A.l Summary statistics of variables

\begin{tabular}{lccccc}
\hline Variable & Observations & Mean & Standard dev. & Minimum & Maximum \\
\hline Conflict & 2550 & -68.4 & 87.3 & -1049.6 & 0.0 \\
Cooperation & 2550 & 34.5 & 34.5 & 0 & 399.6 \\
Net cooperation & 2550 & -33.5 & 73.5 & -946.0 & 280.9 \\
Bad day & 2550 & 0.05 & 3.9 & -38.31 & 213.0 \\
D(TA 100) & 2550 & 21.7 & 74.1 & -199.4 & 263.1 \\
\hline
\end{tabular}

